\title{
The role of emergency medicine residents during the global SARS-Cov-2 pandemic: The Pavia experience
}

\author{
Gianmarco Secco, Giovanni Cappa, Bruno Barcella, Stefano Perlini \\ Emergency Medicine Postgraduate Training Program, University of Pavia, and Emergency Department, \\ IRCCS Policlinico San Matteo Foundation, Pavia, Italy
}

\begin{abstract}
In late January 2020, the first cases of Covid-19 were diagnosed in Italy. A month later the epidemic broke out in Lombardy bringing along dire consequences. Up to January $23^{\text {rd }} 2021$, the region counted 522,000 cases, and 26.518 deaths on a population of nearly 10 million. For many weeks thereafter tens of emergency COVID-19 patients were admitted every day through the ED requiring further adjustments in the organization of the Hospital, always in close cooperation with the out-of-hospital Emergency network. Among these, important and time-sensitive changes took place in the role of Residents in Emergency Medicine. As residents who worked through the first and second wave of the Sars-CoV-2 pandemic in the Emergency Department, we would like to discuss the consequences of our massive involvement on the front line of the healthcare effort to fight it.
\end{abstract}

\section{Introduction}

In late January 2020, the first cases of COVID-19 were diagnosed in Italy. A month later the epidemic broke out in Lombardy bringing along dire consequences. Up to January $23^{\text {rd }} 2021$, the

\footnotetext{
Correspondence: Gianmarco Secco, Postgraduate School of Emergency Medicine, and Emergency Department, IRCCS Policlinico San Matteo, viale Camillo Golgi 19, 27100 Pavia, Italy.

E-mail: secco.gianmarco@gmail.com

Key words: COVID-19; resident; emergency unit; SARS-CoV-2; Pavia.

Conflict of interest: No one. This work was not supported by any grant.

Availability of data and materials: All data generated or analyzed during this study are included in this published article.

Ethics approval and consent to participate: Not applicable.

Consent for publication: Not applicable.

Received for publication: 15 March 2021.

Revision received: 15 March 2021.

Accepted for publication: 15 March 2021.

This work is licensed under a Creative Commons Attribution 4.0 License (by-nc 4.0).

CCopyright: the Author(s), 2021

Licensee PAGEPress, Italy

Emergency Care Journal 2021; 17:9747

doi:10.4081/ecj.2021.9747
}

region counted 522,000 cases, and 26.518 deaths on a population of nearly 10 million.

Since the beginning of the outbreak, San Matteo University Hospital was heavily involved in the epidemic, due to its proximity to the Lodi district, the first "red zone" in Italy (and in the western countries). In order to avoid hospital spread of the infection, starting March 1st 2020, a Covid-19 dedicated Emergency Department (ED) was created. ${ }^{1}$ The COVID-19 ED processed more than 500 suspected cases during the first week and took care of the diagnosis and first management of patients with Sars-CoV-2 pneumonia. For many weeks thereafter tens of emergency COVID-19 patients were admitted every day through the ED requiring further adjustments in the organization of the Hospital, always in close cooperation with the out-of-hospital Emergency network. ${ }^{2}$ Among these, important and time-sensitive changes took place in the role of Residents in Emergency Medicine, as well as in other medical specialties. Initially, residents worked in pairs with emergency physicians, helping them to handle the clinical workout and the massive load of paperwork. Very soon, the growing wave of the pandemics with the inherent increased need of medical doctors (that was further stimulated by infection of part of the healthcare personnel) forced a major change. Government administration issued temporary contracts for $4^{\text {th }}$ and $5^{\text {th }}$ year residents, to provide an increased salary for the higher number of working hours and the assumption of full responsibilities in patients' care. In the meanwhile, younger residents continued to assist attending physicians to the best of their capabilities. As residents who worked through the first and second wave of the Sars-CoV-2 pandemic in the Emergency Department, we would like to discuss the consequences of our massive involvement on the front line of the healthcare effort to fight it.

\footnotetext{
A break in the residency program

Overall, formal education for medical residents, which was based on weekly classes, was stopped, for both the need of enforcing both residents and teachers in the everyday clinical work and the prohibition of all forms of gathering due to lock-down and distancing. Moreover, the rotations in the different wards had to be stopped. In Pavia, as in other postgraduate programs, Emergency Medicine Residency includes multiple rotations in other departments, such as Radiology, Gynecology, Trauma and Orthopedics, Coronary Care Unit, Stroke Unit, Intensive Care Unit, and others. Since all the residents in those rotations were called to cover shifts in the COVID ED, many lost their chance to practice in these departments and will have to recover part of the education they were planned over their 5-years residency program. Residents in surgical branches were even more affected since all non-emergency surgery was cancelled or deferred, due to the pandemics.
} 


\section{Long working hours}

The creation of an additional dedicated ED meant additional shifts for the whole healthcare personnel: doctors (both attending and residents), nurses and technicians. Infection of part of the health professional further increased the need of unscheduled shifts and out-of-hours work. Nobody was counting working hours anymore, and many residents and attendants happened to work 80100 hours per week. Day leave dropped to almost none, with fatigue and stress accumulation becoming a problem, with the inherent risk of burnout.

\section{A stressful working environment}

The introduction of facemasks and other personal protections changed our working routine overnight. We had to dress up with Tyvek suits, gloves, goggles and facemasks, and had to give much care to dressing and undressing procedures with which we were unfamiliar. Drinking or going to the toilet became unforeseen problems, and sweating was a constant state. Communication was also profoundly impaired: talking to colleagues became hard, but even harder it was dealing with patients, who were often elderly with hearing problems and a feeble voice. Not to add the communication with patient's relatives at home. Yet, we were lucky that protective suits and FFP2 masks were available from the beginning and for everyone, while in other hospitals they were scanty, in some cases forcing the personnel to face an increased risk of infection. During our shifts we had to cope with many other stressful conditions, the stronger of which was probably the fear of being affected by Sars-CoV-2 or, worse, of bringing the virus inside our home and infecting our loved ones. Some colleagues started to share a house in order not to put their families at risk. A further level of difficulty, especially for non-experienced doctors, was the need to concomitantly deal with high numbers of patients at the same time, many of whom were in critical conditions. Difficult breathing is an unpleasant condition for those who experience it, as well as emotionally affecting the healthcare personnel who is taking care of patients in such a critical condition. ${ }^{3}$ Moreover, we had to witness the death of many patients in front of our eyes as we had never seen before (and, hopefully, we will never see again).

\section{A chance for improving professional as well as techni- cal skills}

Beyond being stressful, any crisis is indeed a source of new opportunities. In famous quote, Albert Einstein reminded everybody that:

"A crisis can be a real blessing to any person, to any nation. For all crises bring progress. Creativity is born from anguish, just like the day is born form the dark night. It is in the crisis that is inventiveness, discoveries and great strategies." (1955)

As Emergency Medicine Residents, we had a major chance to reshape and improve our training experience, in our humanity as well as in our professional attitude. Some examples might explain this window of opportunity that was provided during these hard and challenging times. One first example is represented by lung ultrasound, which was soon recognized as a useful tool for assessing and monitoring lung involvement in COVID-19 patients. ${ }^{4}$ Thus, residents were trained to use this imaging technique and had the chance to perform hundreds of ultrasound examinations, acquiring considerable skills directly "on the field". Similarly, residents became more confident in the use of advanced oxygen delivery techniques like high flow nasal cannula and Continuous Positive Airway Pressure (CPAP). Moreover, the emerging of a new disease stimulated research in fields as varied as SARS-Cov2 biology, COVID-19 physiopathology, imaging and laboratory diagnostic tools, ventilation and drug treatments. Several research studies were started, and residents played a major role in their design, conduction, discussion, and presentation of the results. For some of the younger residents this represented the first-time to be part of a research team, to have the opportunity to witness all the processes behind a research study and to be an active part of it from planning to data collection, from the use of statistical software to the editing of a scientific paper. ${ }^{5}$ Despite all the difficulties and their heavy shifts, residents managed this task with enthusiasm, recognizing that research was the only way to tackle and come ahead of a very little known disease.

\section{Conclusions}

From this dramatic context, numerous positive elements emerge. First of all, we would mention the strong medical and human collaboration that grew among specialists of different branches, and more in general among all people working in the hospital. We saw orthopedic surgeons learning lung ultrasound from emergency physicians, and doctors and nurses from the wards coming to help in the ED, while ED doctors would move to the wards helping with worsening patients. The human side prevailed over fatigue, teaching us a wonderful lesson. In several occasions we saw fear and despair in a glance among residents, and as often we found in each other's eyes the comfort of knowing that we weren't alone. But it wasn't only colleagues to help. Throughout our (short!) career, we have never received such a strong solidarity from the population, and this was the fuel that pushed us forward every day. Moreover, for the first time we felt we were not acting as students any more, but as doctors in their full capacity, having become an important part of our hospital and of the health system. Moreover, we felt a full support by the attending physicians, by our tutors and mentors as well as by nurses.

We believe that all this was worth the price of a lag in our residency rotations, of increased working hours and of being stressed at times both in our bodies and in our minds. For sure we'll remember for ever this difficult time and this very exceptional chance we had to experiment ourselves as doctors. We are confident that having faced the SarsCov-2 pandemic will give us a higher probability to become better ones.

\section{References}

1. Asperges E, Novati S, Muzzi A, et al. Rapid response to COVID19 outbreak in Northern Italy: how to convert a classic infectious disease ward into a COVID-19 response centre. J Hosp Infect 2020;105:477-9.

2. Perlini S, Canevari F, Cortesi S, et al. Emergency Department and Out-of-Hospital Emergency System (112-AREU 118) integrated response to Coronavirus Disease 2019 in a Northern Italy centre. Intern Emerg Med 2020;15:825-33.

3. Pasin L, Sella N, Correale C, et al. Pandemic COVID-19: the residents' resilience. Acta Biomed 2020;91:e2020120.

4. Secco G, Delorenzo M, Zattera C, et al. Lung ultrasound in COVID-19: a useful diagnostic tool. Emerg Care J 2020;16:35-8.

5. Secco G, Delorenzo M, Salinaro F, et al. Lung ultrasound presentation of COVID-19 patients: phenotypes and correlations. Intern Emerg Med 2021;1-11. 